\title{
Analysis of structure-forming role of phosphogypsum in the production of nonfired cementless building composites
}

\author{
Olga Kukina ${ }^{1, *}$, Andrey Eremin ${ }^{1}$, and Dmitriy Shuvaev ${ }^{1}$ \\ ${ }^{1}$ FSBEI of Higher Education "Voronezh State Technical University", Moscovskiy prospect, 14, \\ Voronezh, 394026, Russia
}

\begin{abstract}
The working hypothesis is the development of the theory of disperse system aggregative stability considering the condensation processes of structure-forming of nonfired cementless building materials on the basis of phosphogypsum. The results of phisicomechanical and physicochemical analyses of Uvarovo chemical plant phosphogypsum are presented. To define the properties of phosphogypsum and phosphogypsum-based composite modern methods of analysis were applied with the use of the following equipment: the universal electromechanical test system Instron, the automatic diffractometer PANalytical EMPYREAN, the device for synchronic thermal analysis. The results of the research showed that the first endoeffects of Uvarovo chemical plant phosphogypsum have the dehydration energy of more than 200 joule/g, and they do not get lost within the time; this proves of the cementing properties of phosphogypsum. Due to the analysis of the differential scanning calorimetry results of phosphogypsum, pressed at 5 $\mathrm{Mpa}$, it was found out that at the models compression the dehydration energy increases, and the correlation between the changes of water films' thickness and dehydration energy can be observed. With the decrease of water films' thickness we can observe the increase of dehydration energy with the simultaneous increase of the structure density and its transformation into a monolithic structure.
\end{abstract}

\section{Introduction}

The problem of phosphogypsum utilization is one of the most significant ecological problems all over the world [1-4]. This problem is usually solved by developing new technologies in the construction sector in the areas of road building, production of gypsum and anhydrite cementing, the filler in the building mixes. The economic effieciency of the immediate use of phosphogypsum and the products of its processing instead of traditional natural raw material in the construction sector in different areas has the following indices: road building $-5.4 \%$; the production of gypsum cementing - $2.5 \%$; the production of anhydrite cementing for construction $-3.9 \%$; the producion of the filler $-21-53 \%$ [5].

\footnotetext{
*Corresponding author: u00136@vgasu.vrn.ru
} 
We may single out several ways of using phosphogypsum: as one of the cementing component in the production; while manufacturing the fillers [6], in the production of gypsum plasterboard without using paper and fiber [7], in the manufacture of wall goods, for instance, bricks by the kilning technology [8]; while manufacturing loess [9], in road building; in nonfired technologies of obtaining wall goods and pavement tiles. Nonradioactive rare-earth metals, which are of a great demand on the market and are used in the war and semiconductor industries, are extracted from phosphogypsum [10-13]. An autoclave way of processing phosphogypsum into the gypseous cementing is known; it happens when phosphogypsum of the moisture up to $55 \%$ from the sulfuric acid production workshop is supplied to the receiving bunker of the workshop where it is processed into the gypseous cementing. The obtained gypseous cementing can reach the durability of $40-50 \mathrm{MPa}$, and water needs are $30-36 \%$ [14]. From waste phosphogypsum it is possible to get water-resistant anhydrite cementings by kilning it with the additions of alumosilicious materials, which reach the compression strength of dry models up to $10-15 \mathrm{MPa}$ in the mortars with sand [15]. To get mortars from phosphogypsum with high-durability performances they apply grinding in the vibration grinding mill $[16,17]$. Composite water-resistant gypseous cementing is also got by combined grinding of fine-ground mortar of dross and gypsum of calcium sulfate dihydrate [18]. Phosphogypsum can be used in the production of building materials as a basis for crystallization structures, but not for the cementing, thus offering the challenge of its largescale use in the industry $[19,20]$. It will be impossible to bring the gypsum dihydrate particles together to the required distance by the casting technology, that is why we propose our own method of molding such systems. There is a technology of producing decorative tiles from phosphogypsum by pressing aqueous pastes with a simultaneous water derivation $[21,22]$. A cheaper and less resource-demanding method is known. Pressing of harsh mixes, containing $70-80 \%$ of phosphogypsum, $20-30 \%$ of gypsum, anhydrate or sulfatecindery cementing under pressure of 5-20 MPa gives the opportunity to manufacture products with the ultimate strength under compression of $5 \mathrm{Mpa}$ and more, which also provides an opportunity to use widely the obtained mix for production of blocks $[23,24]$.

As a working hypothesis the authors of the paper offer the next theoretical propositions, following from the theory of the aggregative stability of colloidal systems. While mixing the components of the raw meals, the water is absorbed in the form of films on the hydrophilic particles. The interaction forces of electrical nature and the disjoining pressure quantity are of the highest values. The maximum durability characteristics of the obtained materials are got if the water films' thickness is $10^{-9}-10^{-7} \mathrm{~m}$. The total energy of the composite interacting particles also comprises induction interaction and dispersion forces of intermolecular interaction $[12,13]$.

Besides, during the semidry molding, used in the nonfired technology of producing building materials, jointing of the particles at their contact results in the relaxation of the charged particles to the boundary zone and structure formation with the minimum junction energy in the particles contact zone. The energy stability of the contacting particles zone and the material density depend on the amount of lattice vacancies in the crystal volume:

$$
N_{v}=N e^{\left[-\left(\frac{E_{v}+P_{v}}{K T}\right)\right]}
$$

where $N_{v}$ is the amount of point imperfections (lattice vacancies in the crystal); $N$ is the total amount of sites; $E_{v}$ is the thermal energy of the crystal activation; $P_{v}$ is the pressure against the crystal; $K$ is Boltzmann constant; $T$ is temperature [25].

At the temperature of $65 \ldots 70^{\circ} \mathrm{C}$ and the change of aqueous extracts $\mathrm{pH}$ from 2 to 8 water films change their thickness dramatically. At the same temperatures the water penetrability increases dramatically, too. 
Dispersed materials with the hydration energy more than 200 joule/g can develop cementing properties [26-29].

The aim of the given paper is to determine the structure-forming role of phosphogypsum while producing nonfired cementless building composites. To achieve the aim the authors of the paper set the following tasks: to analyze physicomechanical and physicochemical properties of phosphogypsum as a dispersed material and artificial stone, to determine its cementing properties, considering the thickness of water films, and energy stability of the contacting particles zone during the condensation.

\section{Materials and Methods}

The phosphogypsum, produced by Uvarovo chemical plant, was used for the research. The physicomechanical properties of the materials were estimated in the Center of common use in Voronezh State Technical University according to the requirements of the State Standards SS 23789-79, SS 8736-93, SS 5802-86, SS 310.4.81, SS 22688-77, and SS 12579 with the help of the universal electromechanical test system Instron 5982 with an error of $\pm 0.5 \%$ when being loaded. The radiography phase analysis was done by the automatic diffractometer PANalytical EMPYREAN. Differential scanning calorimetry DSC was done by the synchronic thermal analysis device STA 449 F5 A-0082-M (NETSCH, Germany) with the software NETSCHProteusco, with the integrated reliable monolithic system of weights and extremely sensitive DSC- and DTA-sensors in the modern construction of STA 449 F3 Jupiter ${ }^{\circledR}$.

The analysis of the materials' microstructure was done by a scanning electronic microscope JSM-6380LV. The pictures present the microstructure of the chips' surface of the models. The micron marker in the pictures allows evaluating the grain dimensions and intergranular thicknesses of the water films.

\section{Results}

Chemical and granulometric composition of the phosphogypsum produced by the mentioned above enterprises is presented in Tables 1 and 2 .

Table 1. Chemical composition of the phosphogypsum (mass \%).

\begin{tabular}{|c|c|c|c|c|c|c|c|c|}
\hline Enterprise & $\begin{array}{c}\text { Total } \\
\text { moisture }\end{array}$ & $\mathbf{p H}$ & $\mathbf{P}_{\mathbf{2}} \mathbf{O}_{\mathbf{5}}$ & $\mathbf{F}$ & $\mathbf{C a O}$ & $\mathbf{S i O}_{\mathbf{2}}$ & $\mathbf{F e}_{\mathbf{2}} \mathbf{O}_{\mathbf{3}}$ & $\mathbf{S O}_{\mathbf{3}}$ \\
\hline $\begin{array}{c}\text { Uvarovo } \\
\text { chemical plant }\end{array}$ & $\begin{array}{c}15.50- \\
20.0\end{array}$ & $\begin{array}{c}7.15- \\
8.02\end{array}$ & $6-7$ & - & $27-28$ & $1-2$ & $2-3$ & $40-42$ \\
\hline
\end{tabular}

Table 2. The results of the grain-size analysis of the waste phosphogypsum of Uvarovo chemical plant.

\begin{tabular}{|c|c|c|c|c|c|c|}
\hline \multirow{2}{*}{ The name of the residue } & 2.5 & 1 & 0.63 & 0.315 & 0.16 & $\begin{array}{c}\text { Pass through } \\
\text { the sieve with } \\
\text { 0.16 net, } \\
\text { mass \% }\end{array}$ \\
\cline { 2 - 7 } & \multicolumn{7}{|c|}{ The sieve residues, mass \% } \\
\hline Particular & 13.78 & 8.74 & 9.0 & 17.86 & 30.82 & 19.80 \\
\hline Total & 13.78 & 22.52 & 31.52 & 49.38 & 80.20 & - \\
\hline
\end{tabular}

Figure 1 presents the diffraction pattern of the waste phosphogypsum model from Uvarovo chemical plant, having the following phases:

a) semiacquatic gypsum $\mathrm{CaSO}_{4} \quad 0.5 \mathrm{H}_{2} \mathrm{O}$ with a hexagonal crystal lattice $\mathrm{a}=6.93 \AA$; b $=6.93 \AA ; \mathrm{c}=6.34 \AA$ with interplanar spacings $\mathrm{d}=6.01 ; 3.47 ; 3.00 ; 2.80 ; 1.84 ; 1.69 \AA$; 
b) two-acquatic gypsum $\mathrm{CaSO}_{4} 2 \mathrm{H}_{2} \mathrm{O}$ with a monoclinic crystal lattice a $=7.61 ; 6.28$ $\AA ; b=15.20 \AA ; c=6.52 \AA$ with interplanar spacings $d=4.28 ; 3.06 ; 2.87 ; 2.68 ; 2.08 \AA$.

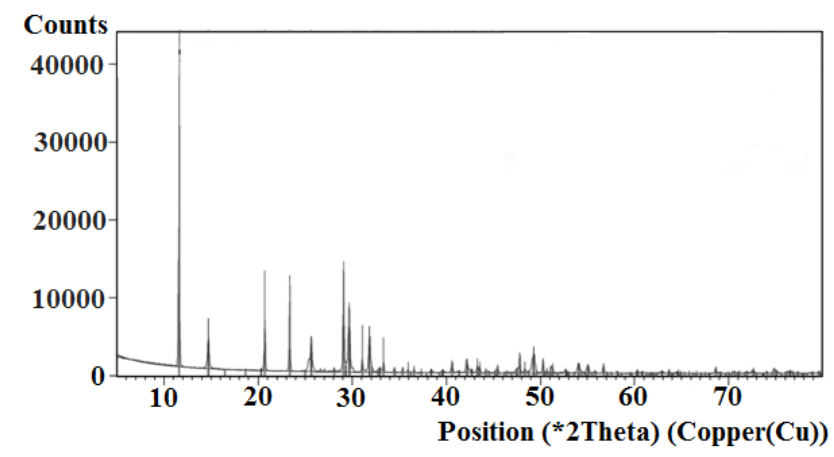

Fig.1. The diffraction pattern of the waste phosphogypsum of Uvarovo chemical plant.

Figure 2 presents a microphotograph of the waste phosphgypsum model from Uvarovo chemical plant.

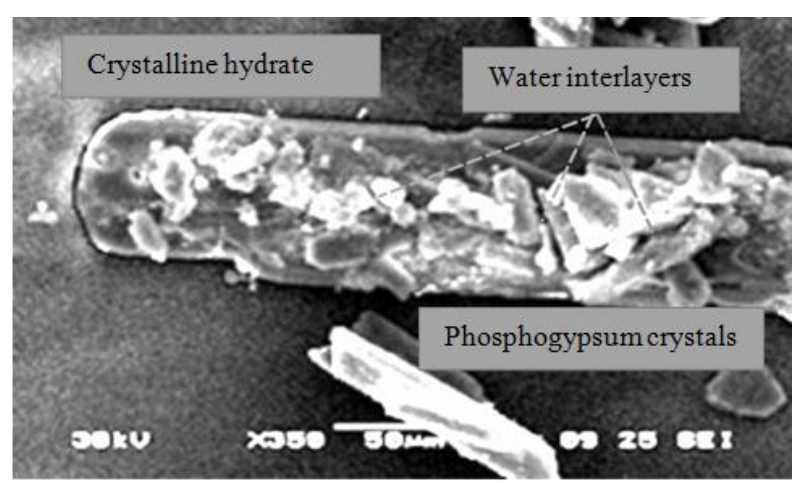

Fig.2. The microphotograph of the waste phosphogypsum model from Uvarovo chemical plant.

Figure 3 presents the data of the differential scanning calorimetry of the waste phosphogypsum model from Uvarovo chemical plant.

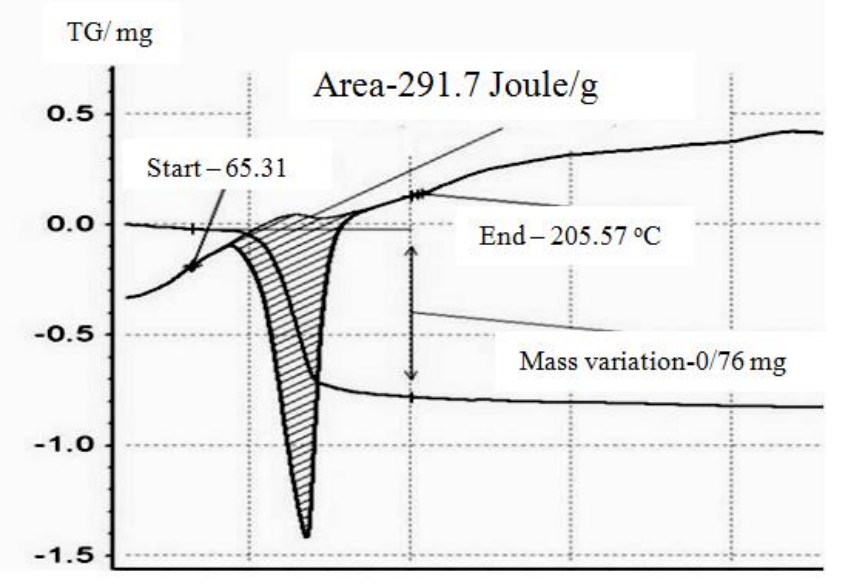

Fig. 3. The result of the differential scanning calorimetry of the waste phosphogypsum from Uvarovo chemical plant (the dehydration energy is $291.7 \mathrm{joule} / \mathrm{g}$ ). 


\section{Discussions}

The research was carried out to scrutinize physicomechanical, physicochemical and cementing properties of phosphogypsum as well as to obtain nonfired cementless composite building material on its basis. Phosphogypsum is a dispersed powder on the surface of which both adsorptive and crystallized water can be kept.

The prisms of a typical ionic crystalline hydrate with the dimensions from 100 to 500 micro lengthwise and from 10 to 100 micro in width can be seen clearly. Besides, water interlayers inside these crystalline hydrates with the thickness from 10 to $1000 \mathrm{~nm}$ can be seen well as the distances between the crystalline hydrate particles are too big (the interstices between them exceed $100 \mathrm{~nm}$ ), and the number of the contacts is small (Fig. 2).

The results of the differential scanning calorimetry show that the first endoeffects of Uvarovo chemical plant phosphogypsum have the dehydration energy of more than 200 joule/g, and they do not lose it within the time; this proves of the cementing properties of phosphogypsum [12-13].

By analyzing the results of the differential scanning calorimetry of phosphogypsum, pressed at $5 \mathrm{Mpa}$ and at the age of 1, 3, 24 days, it was found out that at the compression, leading to tightening, the models demonstrate the dehydration energy increase, and the correlation between the changes of water films thickness and dehydration energy can be observed. With the decrease of water films' thickness we can watch the increase of dehydration energy with the simultaneous increase of the structure density and its transformation into a monolithic structure (Fig. 4).

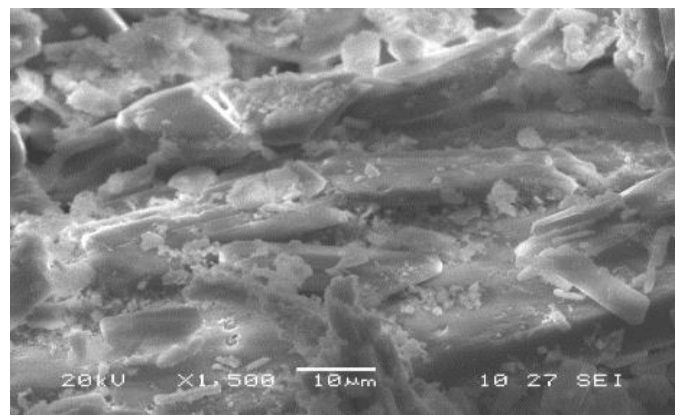

Fig. 4. The microphotograph of the pressed waste phosphogypsum $(\times 1500)$.

Nonfired cementless composite building material was got by semidry molding from phosphogypsum with the addition of sand and slack lime. The results of researching the physicomechanical properties of the products, manufactured from the composite of phosphogypsum $(60 \%)$, sand $(30 \%)$, lime $(10 \%)$ under the laboratory conditions on the compression equipment "Condor", are presented in Table 3.

Table 3. The physicomechanical properties of the products, manufactured from the composite of phosphogypsum (60\%), sand (30\%), lime (10\%) under the laboratory conditions on the compression equipment "Condor".

\begin{tabular}{|l|c|}
\hline \multicolumn{1}{|c|}{ Property } & Value \\
\hline Average strength, $\mathrm{MPa}$ & $3 \ldots 5$ \\
\hline Water absorption & 0.23 \\
\hline Softening coefficient & 0.63 \\
\hline Density, $\mathrm{kg} / \mathrm{m}^{3}$ & 1700 \\
\hline
\end{tabular}

The prime cost of producing $1 \mathrm{~m}^{3}$ wall gypseous materials, depeding on the equipment efficiency, varies from 900 to 1950 rouble $/ \mathrm{m}^{3}$, which is 2 or 3 times cheaper than the counterparts. 


\section{Conclusion}

According to the data of the radiography phase analysis there were no new formations found in the structure of the lime-sandy phosphogypsum material. That is why we may assert that the durability of the materials, got by the nonfired technology, is obtained due to the self-organization of the structure, in which the particles of the dispersed material (phosphogypsum) with the dehydration energy of more than 200 joule/g play the main structure-forming role.

The components with nanodimensional particles, having thermodynamic instability, form crystalline contacts with the nanodimensional thicknesses of the water films. The decrease of porous space (the growth of compression pressure, the decrease of the lime mass fraction, the increase of clay components mass fraction, the increase of the contacts' amount between crystals and the decrease of lattice vacancies amount) contributes to the growth of the durability and water resistance of the composite according to the propositions suggested by the authors of the paper.

\section{References}

1. J. Yang, L. Ma, H. Liu, Z. Guo, Q. Dai, W. Zhang, K. Bounkhong, Chemosphere, 248, 125979 (2020)

2. S.N. Zolotukhin, O.B. Kukina, D.I. Shuvaev, M.L. Zolotukhin, Scientific support of Voronezh region: Collected papers of the winners in the contest of VSTU students' and post-graduate students' scientific-research works in the priority spheres of science and technology development, 50-51 (2019)

3. D. Nizevičienè, D. Vaičiukynienè, B. Michalik, M. Bonczyk, V. Vaitkevičius, V. Jusas, Constr. Build. Mater., 180, 134-142 (2018)

4. A.M. Rashad. J. Clean. Prod., 166, $732-743$ (2017)

5. V.V. Ivanitsky, et al., Phosphogypsum and its use (Moscow : Chemistry, 1990)

6. D.S. Liu, C.Q. Wang, X.D. Mei, C. Zhang, Environ. Sci. Pollut., 26 (29), 30533-30539 (2019)

7. J. Zhou, X. Li, Y. Zhao, Z. Shu, Y. Wang, Y. Zhang, X. Shen, Constr. Build. Mater., 243, 118091 (2020)

8. Y. Rakhila, A. Mestari, S. Azmi, A. Elmchaouri, J. Chem., 11 (4), 1552-1563 (2018)

9. K. Gu, B. Chen, Constr. Build. Mater., 231, 117195 (2020)

10. O. Cheremisina, V. Sergeev, A. Fedorov, D. Alferova, E. Lukyantseva, International Multidisciplinary Scientific Geo Conference Surveying Geology and Mining Ecology Managemen - SGEM, 19, 903-910 (2019)

11. L.A. Podolyanets, Opcion, 34, 1491-1508 (2018)

12. S.N. Zolotukhin, O.B. Kukina, D.E. Barabash, IOP Conf. Series: Mater. sci. eng., 687, 022028 (2019)

13. S. Zolotukhin, O. Kukina, V. Mishchenko, S. Larionov, Adv. Intell. Syst. Comput., 983, 339-351 (2019)

14. A.F. Tubolkin, Waste-free production (Leningrad: Knowledge, 1980)

15. A.V. Volzhensky, Mineral cementing agents: tutorial for higher educational establishments (4th Impression, revised and enlarged edition, Moscow: Stroyizdat, 1986)

16. A.V. Terekhov, V.P. Varlamov, Building Materials, 2, 22-24 (1985) 
17. Iu.B. Potapov, Building materials, 7, 37-39 (2003)

18. M.V. Zuev, S.A. Mamaev, M.A. Mikheenkov, A.I. Stepanov, Composite waterresistant gypsum cementing, Bul. 3 (Patent of the Russian Federation 2505504, MPK C04B28/14, C04B7/14, patent holder Limited Liability Company «EVEREST»: 201212993/03, publ. 27.01.2014)

19. V.B. Petropavlovskaya, A.F. Burianov, T. B. Novichenkova, Building materials, 7, 8-9 (2006)

20. V.B. Petropavlovskaya, V.V. Belov, A.F. Burianov, Building materials, 12, 46-47 (2007)

21. I.M. Lyashkevich, G.S. Raptunovich, A.F. Polak, Proceedings of Higher Educational Establishments. Series Building and Architecture, 12, 60-63 (1985)

22. A.F. Polak, et al., Proceedings of Higher Educational Establishments. Series Building and Architecture, 10, 55-59 (1987)

23. R.N. Mirsaev et al., Building materials, 7, 4-6 (2010)

24. R.N. Mirsaev et al., Building materials, 5, 55 (2004)

25. V.I .Solomatov, S.F. Korenkova, Iu.V. Sidorenko Proceedings of Higher Educational Establishments, 2-3, 38- 44 (2001)

26. A.S. Bagdasarov, Building materials, 1, 13-17 (2002)

27. A.T. Baranov, Ash concrete. Porous and dense (Ed. by a member of the USSR Academy of Science prof. S. A. Mironov, Moscow : Stroyizdat, 1960)

28. V.P. Berezovsky, R. I. Kontor, M.A. Matusevich, Building materials, 2-2, 30 (1964)

29. P.I. Bozhenov, Complex use of mineral raw materials and ecology (Publishing House ASV, Moscow, 1994) 